\title{
Adult extracorporeal membrane oxygenation and gastrointestinal bleeding from small bowel arteriovenous malformations: A novel treatment using spiral enteroscopy
}

\author{
Konrad Sarosiek, MD, Hitoshi Hirose, MD, Harrison T. Pitcher, MD, and Nicholas C. Cavarocchi, MD, \\ Philadelphia, $\mathrm{Pa}$
}

Hemorrhagic complications on extracorporeal membrane oxygenation (ECMO) are common because of the need for anticoagulation to maintain the oxygenator and circuitry. Gastrointestinal (GI) bleeding is reported to occur in $3 \%$ to $6 \%$ of patients receiving ECMO, ${ }^{1}$ requiring frequent transfusions and multiple diagnostic and therapeutic interventions. Multiple transfusions can result in volume overload, coagulopathies, and infections leading to significant morbidity and mortality. We present the first published case of GI bleeding from an arteriovenous malformation (AVM) treated with a novel therapy termed "spiral enteroscopy" while the patient remained on venoarterial ECMO.

\section{CLINICAL SUMMARY}

A 48-year-old man without previous coronary risk factors and GI bleeding was found at home to be unresponsive because of a drug overdose. He was intubated for aspiration pneumonia and transferred to the Thomas Jefferson University Hospital. On echocardiography, he was found to have severe left ventricular dysfunction. Despite mechanical ventilation coupled with multiple inotropes, his condition continued to deteriorate. Acute kidney failure, lactic acidosis, and liver dysfunction developed in the patient, and subsequently venoarterial ECMO was initiated via bifemoral percutaneous cannulation. ECMO flow was maintained with 4.5 to $5.0 \mathrm{~L} / \mathrm{min}$ and mean arterial pressure at 65 to $75 \mathrm{~mm} \mathrm{Hg}$. Anticoagulation with heparin was started on postoperative day 1 with a goal prothrombin time of 40 to 50. On postoperative day 10 , there was an acute decrease in the patient's hemoglobin with hemoccult positive stool. Upper endoscopy, colonoscopy, and mesenteric angiography were all negative. At that point, anticoagulation was held for 36 hours, yet the tarry stools persisted while the patient remained on ECMO. A capsule endoscopy was

\footnotetext{
From the Department of Surgery, Thomas Jefferson University, Philadelphia, Pa. Disclosures: Authors have nothing to disclose with regard to commercial support. Received for publication Sept 28, 2011; accepted for publication Oct 25, 2011; available ahead of print Dec 6, 2011.

Address for reprints: Hitoshi Hirose, MD, Department of Surgery, Thomas Jefferson University, 1025 Walnut Street Room 605, Philadelphia, PA 19107 (E-mail: genex@nifty.com)

J Thorac Cardiovasc Surg 2012;143:1221-2

$0022-5223 / \$ 36.00$

Copyright (C) 2012 by The American Association for Thoracic Surgery

doi:10.1016/j.jtcvs.2011.10.067
}

performed that showed multiple sites of bleeding from the small bowel distal to the Ligament of Treitz, and thus this bleeding was out of reach for a conventional upper endoscope (Figure 1). Spiral enteroscopy using the Discovery Small Bowel overtube (Olympus, Tokyo, Japan) was performed in the operating room and confirmed more than 20 bleeding AVMs in the small bowel, which were treated at the same time with electrocautery. After the procedure, the patient did not require further transfusions and the melena resolved. Subsequently, the patient was weaned from ECMO and it was discontinued. The patient was discharged from the hospital without further complications and has had no further episodes of bleeding.

\section{DISCUSSION}

Venoarterial ECMO provides nonpulsatile arterial flow to the body. Studies of left ventricular assist devices demonstrated that GI bleeding is more frequently seen in patients with continuous flow than in pulsating devices, ${ }^{2}$ and such GI bleeding was more frequently due to AVM from the small bowel. ${ }^{3}$ The mechanism of development of intestinal AVM associated with nonpulsatile circulatory devices is unknown. Malperfusion of the intestinal mucosa and tissue

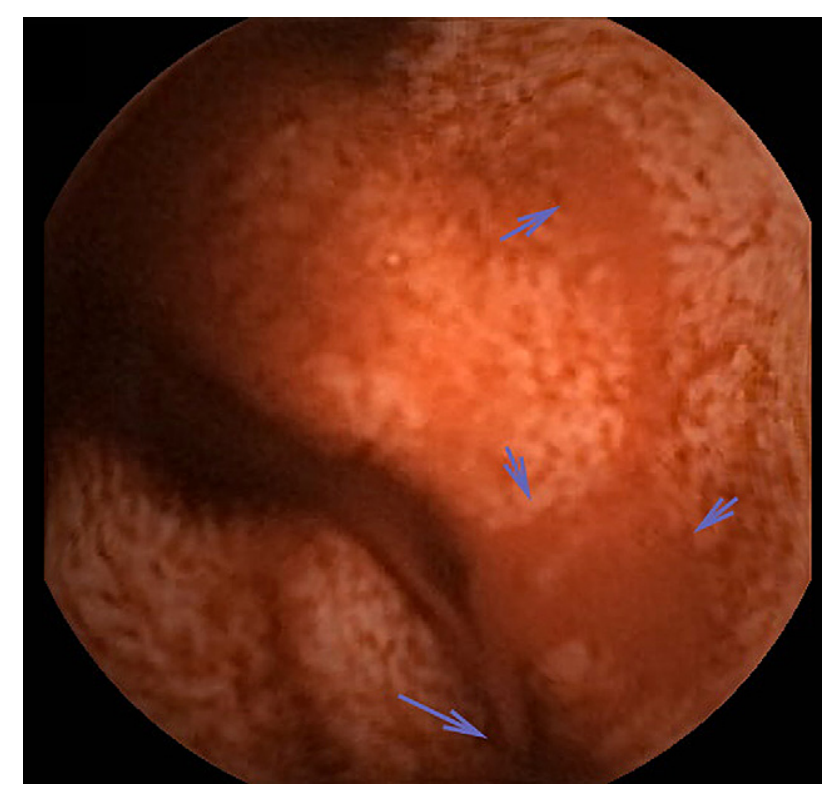

FIGURE 1. Images from capsule endoscopy shows arteriovenous malformations in the small bowel (arrows). 

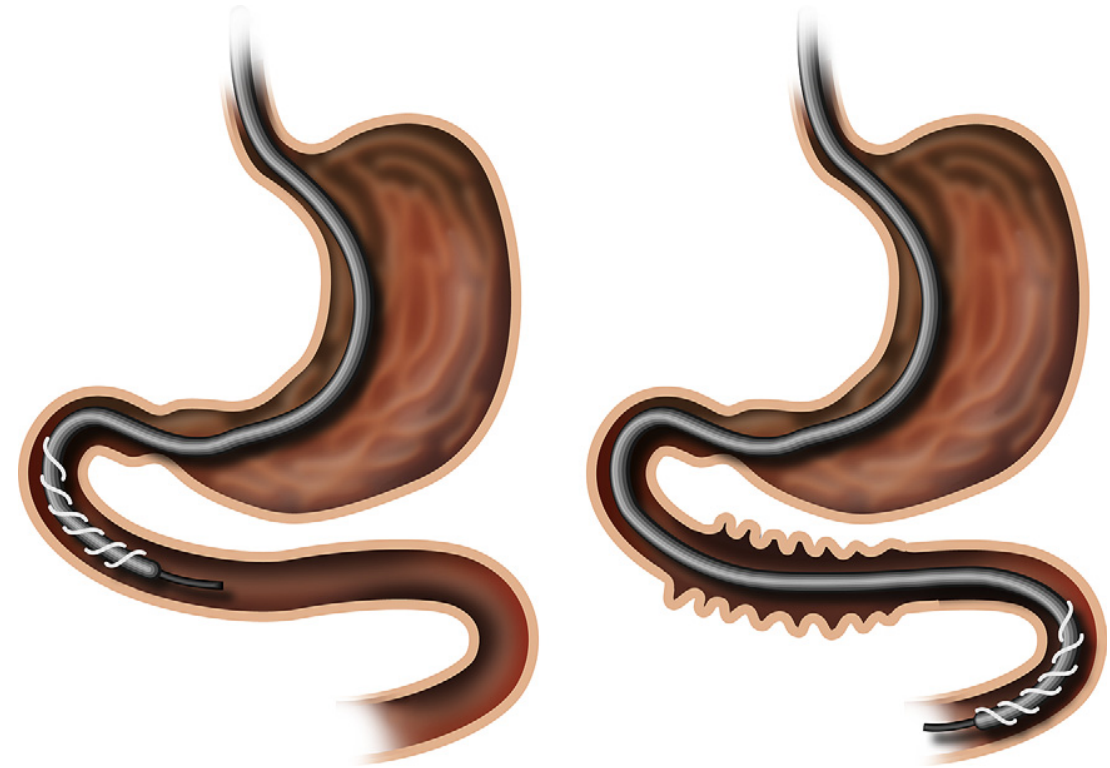

FIGURE 2. Discovery Small Bowel overtube (Olympus, Tokyo, Japan) shows the pleating of the intestine as it is advanced.

hypoxia could lead to restructuring of the mucosal vascular network, which will then be more vulnerable to bleeding. Formation of the intestinal AVM and bleeding can occur even in the patient with short-term nonpulsatile continuous flow mechanical support, such as venoarterial ECMO and other axial flow left ventricular assist devices.

Spiral enteroscopy has been developed to diagnose the small bowel lesions. The technique uses an existing endoscope passed through an Endo-Ease Discovery Small Bowel overtube, which has a raised ridge wrapped from proximal to distal along its length. ${ }^{4}$ First, the overtube is placed in the small bowel beyond the Ligament of Treitz under the guidance of the inner endoscope. Then, clockwise spiral rotation of the overtube is applied so that the small bowel can be pleated over the overtube (Figure 2). The endoscope passing through the overtube visualizes the circumferential distal small bowel, and because it is performed under endoscope guidance, the risk of the bowel perforation is minimal. ${ }^{4} \mathrm{Co}-$ agulation forceps, argon beam instrument, and biopsy forceps can be inserted through the side port of the endoscope, which can be used as additional treatment modalities. Spiral enteroscopy allows for increased visualization of the small bowel distal to the ligament of Treitz. Khashab and colleagues ${ }^{5}$ attained an average distance of $300 \mathrm{~cm}$ with spiral enteroscopy versus $222 \mathrm{~cm}$ with single balloon push enteroscopy. Spiral enteroscopy allows a surgeon to see further and complication rates are lower $(1.9 \%$ vs $3.8 \%)$ compared with the balloon system. ${ }^{5}$

\section{CONCLUSIONS}

Small bowel bleeding traditionally is treated with laparotomy; however, the development of spiral enteroscopy is a new technology to diagnose and treat bleeding from the small bowel distal to the Ligament of Treitz that traditionally has been off limits to endoscopes.

\section{References}

1. Brogan T, Thiagarajan R, Rycus P, Bartlett RH, Bratton SL. Extracorporeal membrane oxygenation in adults with severe respiratory failure: a multi-center database. Intensive Care Med. 2009;35:2105-11.

2. Crow S, John R, Boyle A, Shumway S, Liao K, Colvin-Adams M, et al. Gastrointestinal bleeding rates in recipients of nonpulsatile and pulsatile left ventricular assist devices. J Thorac Cardiovasc Surg. 2009;137:208-15.

3. Demirozu ZT, Radovancevic R, Hochman LF, Gregoric ID, Letsou GV, Kar B, et al. Arteriovenous malformation and gastrointestinal bleeding in patients with the HeartMateII left ventricular assist device. J Heart Lung Transplant. 2011; 30:849-53

4. Morgan D, Upchurch B, Draganov P, Binmoeller KF, Haluszka O, Jonnalagadda S, et al. Spiral enteroscopy: prospective U.S. multicenter study in patients with smallbowel disorders. Gastrointest Endosc. 2010;72:992-8.

5. Khashab M, Lennon A, Dunbar K, Singh VK, Chandrasekhara V, Giday S, et al. A comparative evaluation of single-balloon enteroscopy and spiral enteroscopy for patients with midgut disorders. Gastrointest Endosc. 2010;72:766-72. 